\title{
From Human ETHOLOgY BULLETIN TO HUMAN ETHOLOGY
}

\section{Colin Hendrie}

Editor in Chief

Welcome to Volume 34 of 'Human Ethology'. This sees the start of the third iteration of the publication that started life as the 'Human Ethology Newsletter' (1972/73 - 1995), and that in turn became the 'Human Ethology Bulletin' (1995 - 2018). These various changes of title reflect ISHE's needs of its official journal, progressing from publishing news and information to members to disseminating peer reviewed research and other articles of interest to the wider academic community and beyond.

Human Ethology will publish one volume per year, adding papers to that volume as they are accepted, so as to take full advantage of the immediacy and flexibility of the on-line format. The main thrust of the journal remains studies relating to the direct observation of human behaviour or that of closely related species, although it is emphasised that reviews, theoretical papers and studies relating to replication issues are also welcomed. 'Human Ethology' remains an open source journal that is also free to publish in. 